\title{
Carga y profilaxis de la enfermedad meningocócica invasiva: actualización sobre la vacunación frente al serogrupo B
}

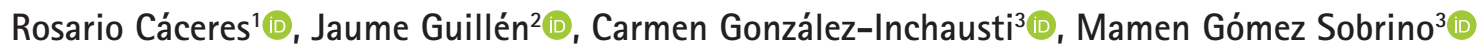 \\ 1. Desarrollo de Proyectos Profesionales y Relaciones Institucionales, Colegio Oficial de Farmacéuticos de Sevilla. 2. Farmacéutico, Santa \\ Perpètua de Mogoda. 3. GSK, Departamento Médico, Madrid.
}

\section{PALABRAS CLAVE}

Infecciones meningocócicas, Neisseria meningitidis, farmacia comunitaria, pandemias, prevención y control, serogrupo B, España, cobertura de vacunación, vacunas

\section{ABREVIATURAS}

4CMenB: vacuna frente al serogrupo meningocócico $\mathrm{B}$ de 4 componentes CAV-AEP: Comité Asesor de Vacunas de la Asociación Española de Pediatría

EMI: enfermedad meningocócica invasiva

fHop: proteina de unión al factor $\mathrm{H}$ IC: intervalo de confianza MenACWY: meningococo (serogrupo) A, C, W e Y MenA: meningococo (serogrupo) $A$ MenB: meningococo (serogrupo) B MenB-FHbp: vacuna frente al serogrupo meningocócico $B$ de 2 componentes

MenC: meningococo (serogrupo) C MenW: meningococo (serogrupo) W MenY: meningococo (serogrupo) Y NadA: adhesina A de Neisseria NHBA: antígeno de unión a la heparina de Neisseria OMS: Organización Mundial de la Salud

OMV: vesícula de la membrana externa

PNI: programa nacional de inmunización PorA: proteína porina $\mathrm{A}$
Recibido: 23/01/2021

Aceptado: 13/05/2021

Disponible online: 06/10/2021

\section{RESUMEN}

La enfermedad meningocócica invasiva (EMI) es una infección bacteriana grave que suele presentarse como meningitis o sepsis. Se transmite por las secreciones de nariz y boca, cursa con síntomas de evolución rápida que, si no se tratan, causan la muerte en 24-48 horas y puede acarrear secuelas devastadoras, como amputación de miembros, convulsiones, ictus y deterioro de la visión, habla y audición. El serogrupo (Men) B es el patógeno responsable de la mayoria de las EMI en Europa, América y Australia.

La Organización Mundial de la Salud considera que la vacunación es el método más efectivo para combatir la meningitis meningocócica. Hasta la fecha no existe ninguna vacuna que proteja de manera conjunta frente a todos los serogrupos causantes de EMI. Las vacunas de polisacáridos conjugados frente a MenACWY se han utilizado durante años, mientras que las dos vacunas frente a MenB han sido desarrollas recientemente. La vacuna MenACWY está incluida en el programa nacional de inmunización español para adolescentes de 12 años. La Asociación Española de Pediatría propone incluir también la vacuna MenB de manera sistemática para lactantes, ya que es el serogrupo más prevalente en España. Los farmacéuticos cumplen, como agentes sanitarios, una misión cotidiana esencial de asesoramiento y dispensación en las farmacias. Esta revisión ofrece información a los farmacéuticos para ayudarles a resolver preguntas sobre la EMI, así como de su profilaxis con vacunas y así, puedan explicar a los padres la importancia de administrar las dosis de recuerdo para completar la pauta de vacunación.

\section{Invasive meningococcal disease burden and prophylaxis: update on serogroup $B$} vaccination

\section{ABSTRACT}

Invasive meningococcal disease (IMD) is a serious bacterial infection commonly presenting as meningitis or sepsis. Transmitted through the mouth and nose secretions, it has rapidly evolving symptoms that can cause death in 24-48 hours if untreated and may also have devastating consequences, such as loss of limbs, seizures, stroke, as well as impairment of vision, speech, and hearing. Serogroup (Men) B is the pathogen responsible for most of cases of IMD in Europe, America, and Australia.

Marcas comerciales: Bexsero, Menjugate, y Menveo son marcas comerciales propiedad de o con licencia del grupo de empresas GSK. Nimenrix es una marca comercial del grupo de empresas GSK, licenciada a Pfizer. NeisVac-C y Trumenba son marcas comerciales de Pfizer Inc.

Financiación: GlaxoSmithKline Biologicals SA financió esta revisión bibliográfica y se hizo cargo de todos los costes asociados al desarrollo y publicación de este manuscrito

Conflicto de intereses: RC y JG notifican que ha recibido honorarios personales del grupo de compañias GSK al margen de este trabajo. CGI y MGS son empleados del grupo de empresas GSK. CGI tiene acciones en el grupo de empresas GSK. Todos los autores no declaran ninguna otra relación o actividad financiera o de otra naturaleza.

Autoría: CGI y MGS concibieron la idea del artículo y realizaron la búsqueda bibliográfica. RC y JG contribuyeron por igual al documento. Todos los autores analizaron e interpretaron la bibliografía publicada y participaron en la elaboración de este manuscrito. Todos los autores tuvieron pleno acceso a los datos y aprobaron el manuscrito final. Todos los autores acordaron rendir cuentas de todos los aspectos del trabajo para investigar y resolver adecuadamente cualquiera relativa a su exactitud e integridad. El trabajo descrito se llevó a cabo de conformidad con las recomendaciones del Comité Internacional de Editores de Revistas Médicas para la realización, presentación, edición y publicación de artículos académicos en revistas médicas. El autor a quien debe dirigirse la correspondencia asumió la responsabilidad de presentar el manuscrito final para su publicación.

Cite este artículo como: Cáceres R, Guillén J, González-Inchausti C, Gómez M. Carga y profilaxis de la enfermedad meningocócica invasiva: actualización sobre la vacunación frente al serogrupo B. Farmacéuticos Comunitarios. 2021 Oct 06; 13 (4): 28-42. doi:10.33620/FC.2173-9218.(2021/Nol13).004.05 Correspondencia: Rosario Cáceres (rosariocaceres@redfarma.org).

ISSN 1885-8619 @SEFAC (Sociedad Española de Farmacia Clínica, Familiar y Comunitaria). Todos los derechos reservados. 


\section{KEYWORDS}

Meningococcal infections, Neisseria meningitidis, community pharmacy, pandemics, prevention and control, serogroup B, Spain, vaccination coverage, vaccines
The World Health Organization considers that vaccination is the most effective approach to defeat meningococcal meningitis. For now, there is no single vaccine that protects against all serogroups causing IMD. Conjugate polysaccharide vaccines against MenACWY have been available for years, and only recently two MenB vaccines have been developed. MenACWY vaccination for adolescents aged 12 years is included in the Spanish National Immunization Program and the Spanish Association of Paediatrics suggests the systematic inclusion of the MenB vaccine as well for infants, as it is the most prevalent serogroup in Spain. Pharmacists play an essential role as healthcare agents, advising and dispensing every day to patients who visit the pharmacy. This review provides information that will help pharmacists to answer questions relevant to IMD and prophylaxis with the available vaccines, so that they can explain to parents the importance of booster doses and vaccination schedule completion.

\section{INTRODUCCIÓN}

La enfermedad meningocócica invasiva (EMI) es una infección causada predominantemente por Neisseria meningitidis (meningococo), que suele presentarse como meningitis o sepsis (1). La enfermedad se presenta con menor frecuencia como neumonía, artritis, conjuntivitis, pericarditis o miocarditis (2). La EMI es temida en el mundo por su rápida evolución y su elevada letalidad: la muerte puede ocurrir en 24-48 horas desde el comienzo de los sintomas (3). Algunos supervivientes sufren secuelas devastadoras $(3,4)$. Como sucede con otras enfermedades infecciosas, desde hace 40 años existen vacunas de polisacáridos y conjugadas (5) específicas para patógenos (serogrupos) concretos (3). Hace poco se han desarrollado dos vacunas de proteínas frente al meningococo grupo B (MenB), una de 4 componentes (4CMenB, Bexsero, GSK) y otra de 2 componentes (MenB-FHbp, Trumenba, Pfizer) y ambas han sido utilizadas frente a brotes (6-8). Además, $4 \mathrm{CMenB}$ se ha introducido en varios programas nacionales de inmunización (PNIs) del mundo $(9,10)$, así como en programas regionales de inmunización, como es el caso de España donde está incluida para la vacunación de lactantes en Castilla y León y las Islas Canarias $(11,12)$.

La vacunación frente a la EMI está incluida en el PNI español que se modificó en 2019: la dosis de la vacuna conjugada del serogrupo $C(\mathrm{MenC})$ para niños de 12 años se sustituyó por la vacuna tetravalente conjugada frente a los serogrupos A, C, W e $Y$ (vacuna MenACWY) (13), con un rescate para adolescentes de 13-18 años que abarcaría un periodo de 2-3 años (13). Las regiones de Castilla y León y Andalucía también incluyen la vacunación con MenACWY a los 12 meses en sus programas $(11,14)$. Este último esquema está recomendado por el Comité Asesor de Vacunas de la Asociación Española de Pediatría (CAV-AEP), que también recomienda incluir en el PNI, a partir de los 2 meses de edad, la vacuna frente al patógeno responsable de la mayoria de las EMI en España, MenB $(15,16)$.
La Organización Mundial de la Salud (OMS) ha fijado 2030 como horizonte temporal para derrotar a la meningitis (3). Se establecieron tres objetivos: erradicar las epidemias de meningitis y reducir en un $80 \%$ los casos y muertes asociadas y en un $50 \%$ el impacto de las secuelas (3). Todas las regiones de la OMS están implementando la hoja de ruta para derrotar a la meningitis con estrategias especificas adaptadas a sus necesidades (3).

Por su parte, la pandemia de COVID-19 ha supuesto una nueva amenaza para las enfermedades prevenibles con vacunas: la interrupción de servicios esenciales ha reducido la cobertura vacunal de forma alarmante (17). Numerosos paises han comunicado a la Alianza Mundial para el Fomento de la Vacunación y la Inmunización la suspensión moderada-intensa o absoluta de los servicios de inmunización durante marzo-abril de 2020. Millones de personas en el mundo corren, por tanto, riesgo de contraer enfermedades prevenibles mediante vacunación (18). Las farmacias pueden contribuir a mantener las coberturas vacunales; así lo sugiere la OMS en su directriz operativa (17). Los farmacéuticos son los profesionales que ocupan la primera línea de atención a los pacientes y cada día deben responder a preguntas sobre enfermedades y su tratamiento. Por eso, reforzar el rol de los farmacéuticos como fuente de información podría contribuir a restablecer los servicios esenciales interrumpidos por la pandemia de COVID-19.

Hemos revisado detalladamente la última evidencia cientifica sobre la EMI y las vacunas disponibles para su prevención, con el fin de ayudar a los farmacéuticos en su rol fundamental como asesores sanitarios. En esta revisión resumimos los conocimientos actuales sobre la patogenia, manifestaciones clínicas y complicaciones de la EMI; también exponemos las características de las vacunas, en particular las vacunas frente a la EMI por MenB. La figura 1 resume el contexto, los resultados y el impacto de esta revisión para los profesionales sanitarios. 


\section{RESUMEN EN LENGUAJE SENCILLO}

\section{¿Cuál es el contexto?}

- La enfermedad meningocócica invasiva, causada por la bacteria Neisseria meningitidis, pone la vida en peligro y puede acarrear secuelas graves, como amputación de miembros, convulsiones y deterioro de la audición, habla y visión.

- En España, se realiza una vacunación sistemática solo frente a ciertos patógenos (serogrupos de Neisseria meningitidis), pero no frente al responsable de la mayoría de los casos (serogrupo B). Hasta hace poco no existía ninguna vacuna especifica.

- Bexsero y Trumenba son vacunas nuevas, diseñadas para combatir el serogrupo B de Neisseria meningitidis.

- Bexsero está indicado para vacunar desde lactantes de $\geq 2$ meses hasta adultos mayores. Trumenba está indicada para vacunar desde niños de 10 años hasta adultos mayores.

- El Comité Asesor de Vacunas de la Asociación Española de Pediatría recomienda incluir Bexsero en el calendario de vacunación sistemática de lactantes y niños pequeños. Ya está incluido en dos programas regionales de inmunización y se espera su inclusión en el programa nacional.

- Realizamos una revisión bibliográfica destinada a los farmacéuticos españoles para recabar la evidencia más reciente sobre la enfermedad invasiva meningocócica y su profilaxis.

\section{¿Qué novedades aporta?}

- Describimos la enfermedad meningocócica invasiva y ofrecemos un resumen de su epidemiología, las vacunas y las recomendaciones sobre inmunización en España.

\section{¿Cuál es el impacto?}

- Este documento aporta información actualizada que ayudará a los farmacéuticos a responder a las preguntas de la población sobre la enfermedad meningocócica y su profilaxis con las vacunas más recientes y a explicar a los padres la importancia de las dosis de recuerdo y la finalización del programa de vacunación.

Figura 1 Resumen en lenguaje sencillo

\section{EPIDEMIOLOGÍA}

Según las últimas estimaciones, en 20183.233 personas sufrieron EMI en 30 países de la Unión Europea/Espacio Económico Europeo (figura 2) (19), 392 de ellas en España. La EMI es endémica (con casos esporádicos), pero también epidémica (con brotes) (20). La incidencia de EMI en Europa varía mucho de un país a otro. Por ejemplo, en 2018 la tasa de notificación varió de 0,00/100.000 habitantes en Islandia a 1,82/100.000 en Irlanda, con una media europea de 0,62/100.000 y una incidencia de 0,84/100.000 en España (19). De 2000 a 2012 la tasa de notificación española sobrepasó la media europea, pero luego disminuyó hasta situarse por debajo a partir de 2013. Sin embargo, en los últimos años ha aumentado y alcanzado de nuevo la media europea (figura 2) (19).
La EMI afecta principalmente a lactantes (menores de 12 meses), seguidos de niños y adolescentes (3), aunque la colonización bacteriana se da más en los adultos jóvenes y es rara en los lactantes (21). En la temporada 2017-2018, en España, la tasa de notificación fue mayor en lactantes y niños de 1-4 años (8,65 y 3,19/100.000 respectivamente) (22). En esa misma temporada, la letalidad total alcanzó 12,7\% en España (346 casos de EMI y 44 muertes) (figura 2) (22).

\section{SEROGRUPOS}

El meningococo es un diplococo gram-negativo que está rodeado por una membrana polisacárida, también conocida 


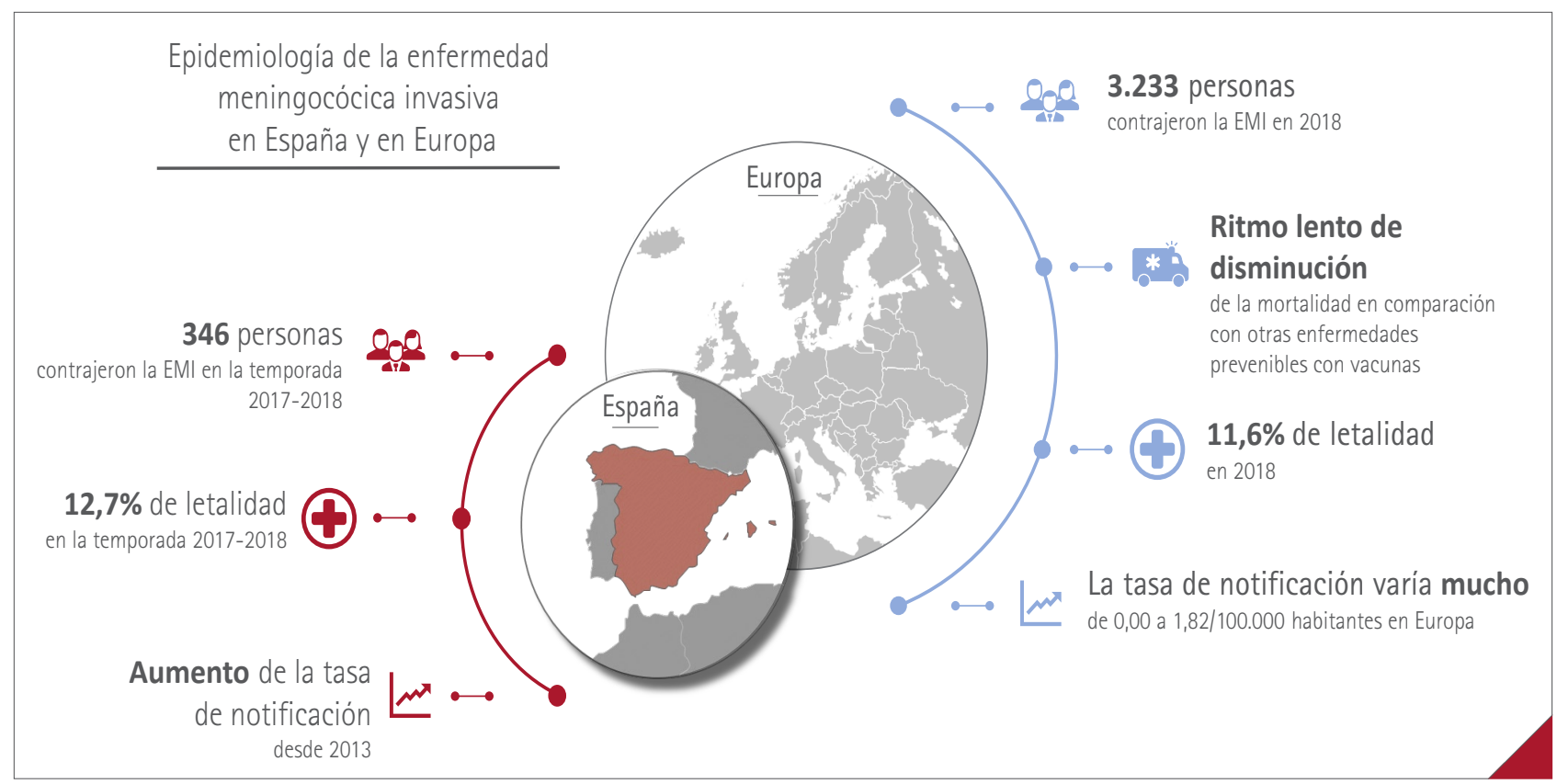

Figura 2 Epidemiología de la enfermedad meningocócica invasiva en España y en Europa

EMI: enfermedad meningocócica invasiva.

En España, el número de casos de EMI y la tasa de letalidad proceden del informe sobre EMI de la Red Nacional de Vigilancia Epidemiológica de España para la temporada 2017-2018 (22) mientras que, en Europa, los datos de 2018 provienen del Atlas de Vigilancia de las Enfermedades Infecciosas del Centro Europeo para la Prevención y el Control de las Enfermedades (se basa en los datos proporcionados por la Organización Mundial de la Salud y los Ministerios de Sanidad de los paises afectados) (19). Conviene señalar que los datos de la Red Nacional de Vigilancia Epidemiológica de España reflejan las estaciones epidemiológicas (de la semana 41 de un año a la semana 40 del año siguiente), mientras que los datos del Centro Europeo para la Prevención y el Control de las Enfermedades reflejan los años naturales.

Fuente: World Health Organization (2020) (3); European Centre for Disease Prevention and Control (ECDC) (2018) (19); Ministerio de Ciencia, Innovación y universidades (2019) (22).

como "cápsula" (1). Se han identificado doce estructuras capsulares distintas que permiten clasificar la bacteria en los subtipos (serogrupos) (1). Seis serogrupos - A, B, C, W, X e Y- son los más habituales y peligrosos y causan una EMI potencialmente mortal $(3,23)$.

La distribución geográfica de los serogrupos varía en el mundo $(19,20,24)$ y cambia a lo largo del tiempo. Está influenciado por las epidemias, la emergencia de nuevos clones virulentos, las opciones de vacunación, los cambios ambientales y otros acontecimientos (25). MenB es una causa importante de EMI en Europa, Norteamérica, Norte de África y Australia; MenC, en Brasil y China; MenA, en India, y MenY, en Japón (figura 3) $(20,24)$. Según las últimas estimaciones del Centro Europeo para la Prevención y el Control de las Enfermedades, en 2018 MenB causó la mitad de todas las EMI en Europa (47,7\%, 1.543/3.233), incluida España $(39,8 \%, 156 / 392)(19)$.

\section{TRANSMISIÓN Y ESTADO DE PORTADOR} Neisseria meningitidisse transmite de una persona a otra por las secreciones de nariz y boca (figura 4) (3). En los lugares concurridos, donde se produce un contacto estrecho entre la gente, se favorece la propagación bacteriana y la adquisición del estado de portador $(3,20)$. Vivir en campus estudiantiles y cuarteles militares o participar en manifestaciones multitudinarias aumentan la probabilidad de infección y brote (20). Algunos factores adicionales de riesgo son las actividades sociales, como el tabaquismo activo o pasivo, los besos o compartir cubiertos y bebidas (figura 4) $(3,20)$.

Neisseria meningitidis coloniza la nasofaringe de personas sanas, predominantemente adolescentes y adultos jóvenes; su frecuencia de colonización aumenta del $5 \%$ en la lactancia al $24 \%$ en la juventud y luego disminuye en la vida adulta $(21,26)$. La adquisición de la bacteria produce una infección grave solo a una minoría $(1,3)$. La nasofaringe ofrece el entorno ideal para la supervivencia bacteriana y alli suele alojarse como comensal asintomático inofensivo; el huésped entonces es "portador" (figura 4) $(1,21)$.

\section{PATOGENIA}

Aunque de manera rara, entre el primer y el decimocuarto día tras la colonización faríngea por Neisseria meningitidis, un subconjunto de "clones hiperinvasivos" $(1,21,27,28)$ penetra en la superficie del epitelio faringeo e "invade" el torrente sanguíneo (1). La EMI comienza a desarrollarse a partir de ese momento (1). Las poblaciones más vulnerables a la 


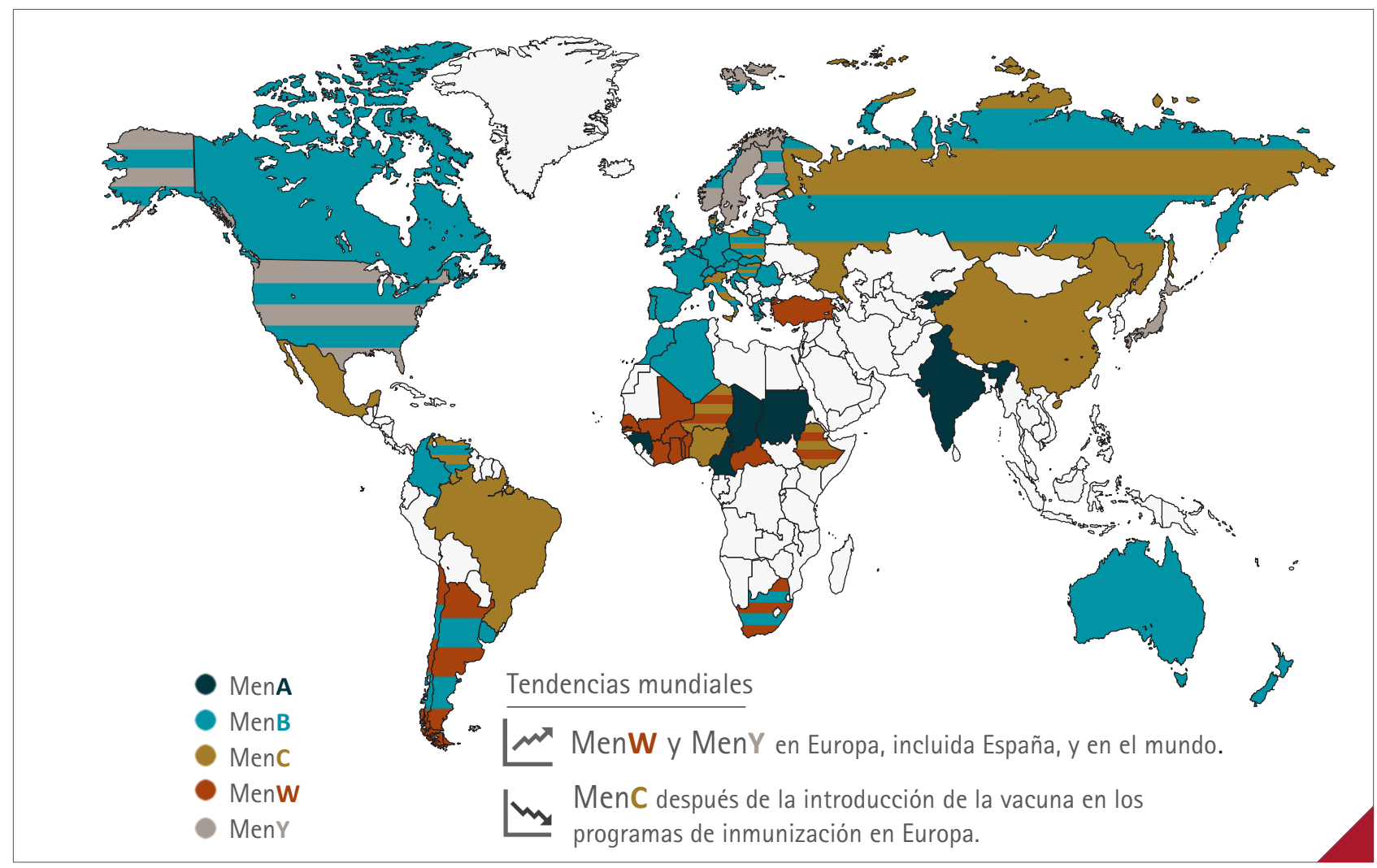

Figura 3 Epidemiología mundial de la enfermedad meningocócica invasiva por serogrupos

MenA: meningococo (serogrupo) A; MenB: meningococo (serogrupo) B; MenC: meningococo (serogrupo) C; MenW: meningococo (serogrupo) W; MenY: meningococo (serogrupo) Y.

Fuente: European Centre for Disease Prevention and Control (ECDC) (2018) (19); Acevedo R, et al (2019) (20); Ministerio de Ciencia, Innovación y Universidades (2019) (22); Peterson ME, et al (2019) (24); Whittaker R, et al (2017) (25).

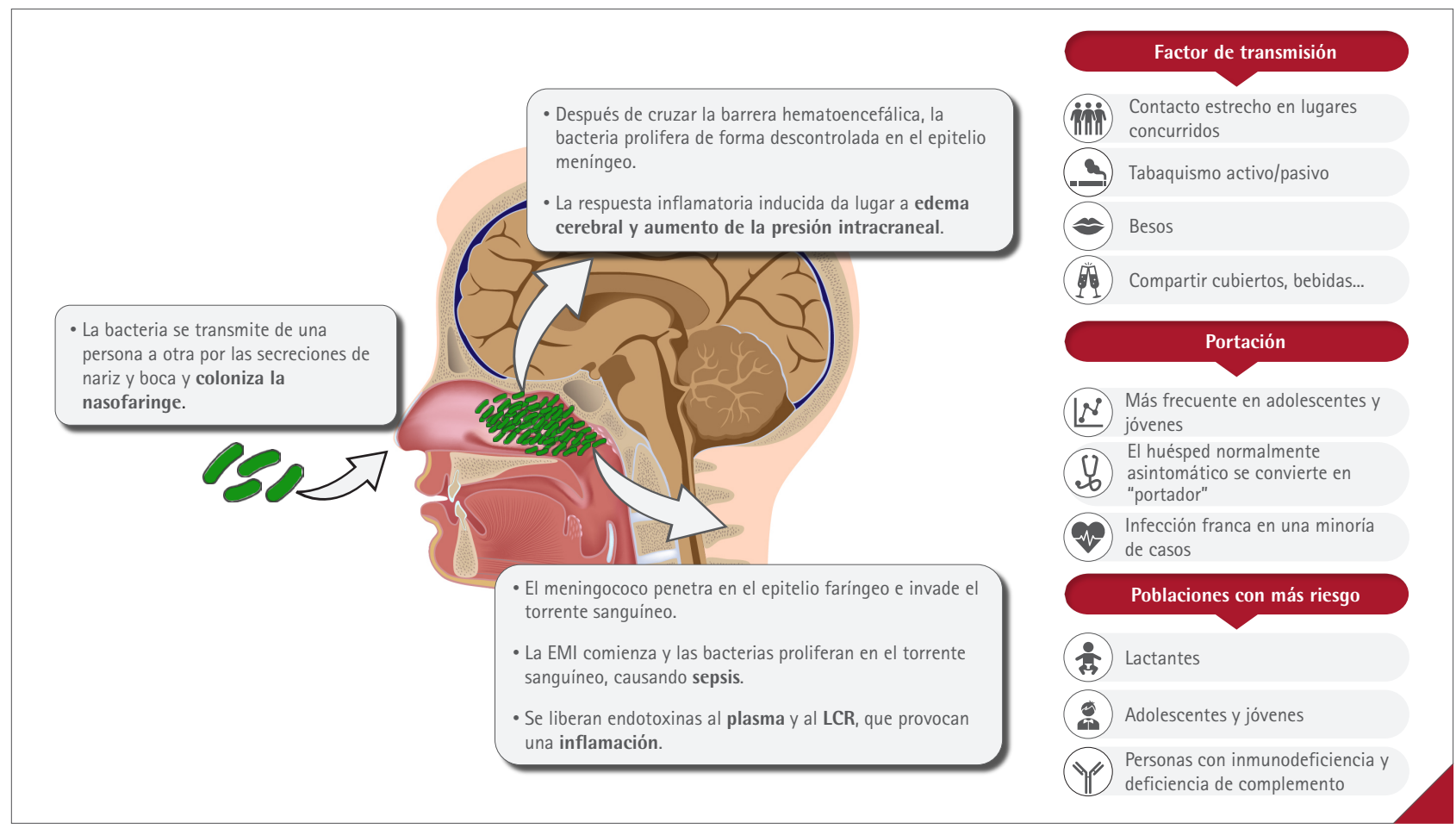

Figura 4 Transmisión, portación y patogenia de la enfermedad meningocócica invasiva

EMI: enfermedad meningocócica invasiva; LCR: liquido cefalorraquideo.

Fuente: Caugant DA, et al (2020) (1); World Health Organization (2020) (3); Acevedo R, et al (2019) (20); Read RC (2014) (21); Christensen H, et al (2010) (26); Coureuil M, et al (2017) (30); Pathan N, et al (2003) (31). 
EMI son lactantes, adolescentes, adultos jóvenes y personas consideradas de riesgo de padecer la enfermedad, como, por ejemplo, personas con asplenia, inmunodeficiencia, deficiencia de complemento o tratadas con eculizumab $(3,20)$.

El meningococo prolifera rápidamente en el torrente sanguíneo causando sepsis. También puede invadir otros órganos, ocasionando una inflamación sistémica u orgánica, o ambas $(1,29,30)$. Los meningococos liberan endotoxinas al plasma y líquido cefalorraquídeo y el sistema inmunitario responde produciendo más citoquinas (31). La meningitis aparece cuando la bacteria atraviesa la barrera hematoencefálica y alcanza las meninges (30). La proliferación meningocócica descontrolada en el epitelio meníngeo induce un proceso inflamatorio que ocasiona edema cerebral y eleva la presión intracraneal (figura 4) (31).

\section{SÍNTOMAS, COMPLICACIONES Y SECUELAS}

La EMI se suele manifestar con dolor de cabeza, fiebre, vómitos, rigidez de cuello, erupción cutánea, fotosensibilidad, irritabilidad, agitación y letargo $(2-5,32,33)$. En el Hospital
Universitario de Bellvitge de Barcelona, más del $80 \%$ de los pacientes ingresados con EMI entre 1977 y 2013 presentaron dolor de cabeza, rigidez de cuello, náuseas o vómitos y lesiones cutáneas (figura 5) (4).

Los sintomas aparecen a los 4 días de media después de la infección; el período de incubación oscila entre 2 y 10 días (3). Al principio, los síntomas pueden ser leves; luego, se agravan enseguida y pueden resultar en insuficiencia orgánica y muerte (2). La gravedad depende de la respuesta inmunitaria (2). No todos los sintomas se observan en todos los pacientes y grupos etarios. Es posible que los recién nacidos no muestren sintomas clásicos, sino un Ilanto sin consuelo; los menores de 2 años pueden sufrir letargo, irritabilidad o ambos (2). En los adolescentes, por ejemplo, la infección por MenW cursa con sintomas gastrointestinales que progresan rápidamente (náuseas, vómitos y/o dolor abdominal, seguidos de diarrea) que a veces producen enfermedad grave e incluso muerte (34).

Según avanza la EMI, pueden aparecer complicaciones neurológicas y sistémicas o discapacidades duraderas, como problemas auditivos (4), crisis epilépticas, ictus, debilidad

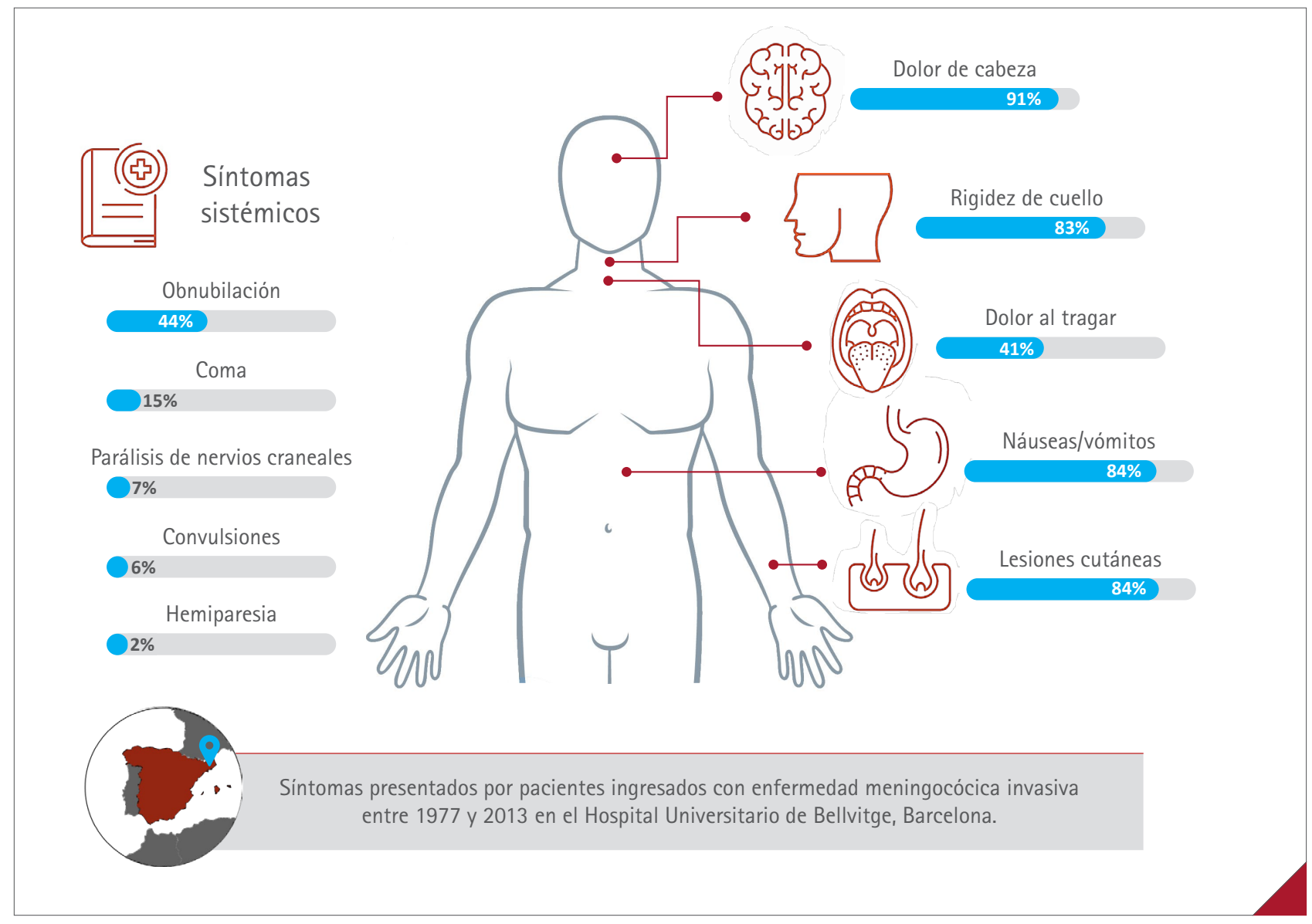

Figura 5 Síntomas observados en pacientes ingresados con enfermedad meningocócica invasiva entre 1977 y 2013 en el Hospital Universitario de Bellvitge, Barcelona

Fuente: Cabellos C, et al (2019) (4). 
en extremidades y trastornos del habla (3). Algunos recién nacidos sufren ventriculitis, hidrocefalia y absceso cerebral (3). En caso de sepsis se precisa la amputación ocasional de dedos de manos y pies o de extremidades (3).

\section{TRATAMIENTO DE LOS CASOS SOSPECHOSOS}

Toda sospecha de EMI constituye una urgencia y requiere ingreso hospitalario (35). Según estadísticas de la OMS, el $50 \%$ de los infectados fallece si no recibe tratamiento y cuidados intensivos inmediatos (3) y más del $10 \%$ experimenta secuelas graves (3). En general, se solicitan pruebas urgentes para confirmar la meningitis y determinar el patógeno concreto, y el tratamiento antibiótico se inicia cuanto antes $(36,37)$ [en la primera hora desde el ingreso (35)]. Conviene recordar que los adolescentes con sintomas tardan en acudir al médico (38) y este es el grupo etario con la letalidad máxima (19). La elección empírica de los antibióticos depende de la edad y del patrón regional de sensibilidad a los antibióticos. El tratamiento se ajusta tras aislar el microorganismo causal (39). Los pacientes con sintomas graves y shock son trasladados a la unidad de cuidados intensivos donde se aplican los procedimientos apropiados $(35,40)$. Pese a los cuidados intensivos inmediatos y una antibioticoterapia eficaz, siguen observándose secuelas graves que dependen de la progresión del proceso inflamatorio hasta ese momento (33). Por eso, la OMS considera que la prevención es la medida más importante de lucha contra la meningitis (3).

\section{PROFILAXIS Y CONTROL}

La profilaxis duradera puede conseguirse administrando las vacunas durante los programas de inmunización sistemática y las epidemias (3). Por eso, la OMS ha designado la vacunación como primer objetivo estratégico esencial de la hoja de ruta para combatir a la meningitis bacteriana (incluida la meningocócica) en 2030 (3). Para ganar esta batalla, uno de los primeros objetivos es facilitar el acceso a las vacunas. Otro objetivo inicial es mejorar el diagnóstico temprano de los patógenos epidémicos (3).

Sin embargo, la vacunación es la estrategia principal, no solo para prevenir los brotes, sino también para controlarlos (41). Durante los brotes hay que administrar vacunas y antibióticos para controlar la enfermedad y reducir su carga (3). La quimioprofilaxis masiva con antibióticos controla la transmisión, al reducir temporalmente la portación antes de que la vacuna ofrezca protección (42). Una vez establecida la enfermedad, esporádica o epidémica, se recomienda proteger a los contactos estrechos de los pacientes con antibióticos, como ceftriaxona, rifampicina y ciprofloxacino (39). Las personas no infectadas cercanas al paciente, como familiares, tutores, maestros $y$ amigos, corren un riesgo de contraer meningitis meningocócica 400-800 veces mayor; la profilaxis con antibiótico reduce este alto riesgo, además de la portación bacteriana (39).

\section{VACUNAS MENINGOCÓCICAS}

La tabla 1 resume las recomendaciones actuales en España para la inmunización sistemática frente a la EMI y las vacunas existentes.

\section{VACUNAS FRENTE A MenACWY}

Han pasado 50 años desde que los bacteriólogos descubrieron que la inmunidad frente al meningococo era específica de serogrupo, plazo suficiente para desarrollar las primeras vacunas polisacáridas frente a la EMI $(43,44)$.

La primera vacuna frente a MenC prácticamente erradicó la enfermedad por MenC en el ejército de los Estados Unidos después de su introducción en el programa de vacunación sistemática de los cuarteles estadounidenses (43). Pronto le siguió la vacuna frente a MenA y a principios de los 80 se introdujo la vacuna polisacárida tetravalente MenACWY (43). Se desarrollaron asimismo vacunas polisacáridas bivalentes ( $A$ y $C$ ) y trivalentes ( $A, C$ y W) (45). Sin embargo, las vacunas polisacáridas mostraban menos inmunogenicidad en los menores de 2 años y no inducían inmunidad duradera $(43,46)$.

Nuevas investigaciones inspiradas en la introducción exitosa de vacunas conjugadas frente a Haemophilus influenzae tipo b revelaron que la conjugación del polisacárido capsular con una proteína portadora reforzaba la inmunogenicidad, al mejorar la memoria inmunitaria y la respuesta primaria de anticuerpos $(43,46)$. De hecho, la introducción de la primera vacuna conjugada monovalente frente a MenC redujo drásticamente la incidencia de EMI en los niños (43). Además, esta vacuna redujo la portación de MenC, es decir, la probabilidad de transmisión a sujetos no vacunados; de esta manera, confirió protección indirecta e inmunidad colectiva $(46,47)$. La vacuna MenC se incluyó entonces en los PNIs sistemática de muchos países (45). Las vacunas tetravalentes frente a MenACWY conjugadas con proteínas se desarrollaron después $(43,45)$.

\section{VACUNAS FRENTE AL MenB}

Las vacunas meningocócicas anteriores a las vacunas actuales frente a MenB se basaban en la cápsula polisacárida. 
Tabla 1 Vacunas meningocócicas disponibles en España y recomendaciones respectivas para 2021 de la Asociación Española de Pediatría (CAV-AEP)

\begin{tabular}{|c|c|c|c|}
\hline $\begin{array}{l}\text { Vacuna } \\
\text { (nombre comercial) }\end{array}$ & Tipo de vacuna & $\begin{array}{l}\text { Serogrupo } \\
\text { cubierto }\end{array}$ & $\begin{array}{l}\text { Recomendación de la } \\
\text { CAV-AEP (15) }\end{array}$ \\
\hline $\begin{array}{l}\text { MenC-TT'1,2 } \\
\text { (NeisVac-C) }\end{array}$ & Polisacárido capsular conjugado con el toxoide tetánico & C & 4,12 meses \\
\hline $\begin{array}{l}\text { MenACWY-CRM }{ }^{2} \\
\text { (Menveo) }\end{array}$ & Polisacárido capsular conjugado con CRM & $A, C, W, Y$ & 12-18 años \\
\hline $\begin{array}{l}\text { MenACWY-T² } \\
\text { (Nimenrix) }\end{array}$ & Polisacárido capsular conjugado con el toxoide tetánico & $A, C, W, Y$ & $\begin{array}{l}12 \text { meses } \\
12-18 \text { años }\end{array}$ \\
\hline $\begin{array}{l}\text { 4CMenB } \\
\text { (Bexsero) }\end{array}$ & Contiene cuatro proteínas subcapsulares & B & $2,4,12-15$ meses \\
\hline $\begin{array}{l}\text { MenB-FHbp } \\
\text { (Trumenba) }\end{array}$ & Contiene dos variantes de la misma proteína subcapsular & B & \\
\hline
\end{tabular}

4CMenB: vacuna frente al serogrupo meningocócico B de 4 componentes; CAV-AEP: Comité Asesor de Vacunas de la Asociación Española de Pediatria; CRM: material de reacción cruzada; EE. UU.: Estados Unidos de América; EMI: enfermedad meningocócica invasiva; MenACWY: meningococo (serogrupo) A, C, W e Y; MenB: meningococo (serogrupo) B; MenB-FHbp: vacuna frente al serogrupo meningocócico B de 2 componentes; MenC: meningococo (serogrupo) C; SPR: sarampión, parotiditis, rubéola; T: toxoide tetánico; VIH: virus de la inmunodeficiencia humana.

La vacuna MenC-CRM (Menjugate) también se comercializa en España.

Vacunación frente a MenC y MenACWY: Una dosis de vacuna conjugada MenC- $T$ a los 4 meses de edad. A los 12 meses y a los $12-14$ años se recomienda una dosis de la vacuna MenACWY, aconsejándose un rescate progresivo hasta los 18 años de edad. Si los padres deciden no administrar la vacuna MenACWY a los 12 meses, se administrará la vacuna MenC-T financiada por la comunidad. Para el resto de las edades la recomendación es de tipo individual. Vacuna MenACWY también se sigue recomendando sobre todo a niños y adolescentes que residan en paises donde la vacuna está indicada a esa edad (EE. UU., Canadá, Argentina, Reino Unido, Austria, Grecia, Holanda, Italia y Suiza) y aquellos con factores de riesgo para EMI: asplenia anatómica o funcional, deficiencia de factores de complemento, tratamiento con eculizumab o ravulizumab, receptores de trasplante de progenitores hematopoyéticos, infección por VIH, episodio previo de EMI por cualquier serogrupo y contactos de un caso indice de EMI causado por el serogrupo A, C, W o Y en un brote. Quienes viajen a la Meca por motivos religiosos y al llamado cinturón africano de la meningitis durante la estación seca también recibirán MenACWY.

Vacunación frente a MenB con 4CMenB: 3 dosis a partir de los 2 meses de edad: 2 dosis separadas 2 meses y 1 recuerdo a partir de los 12 meses, si han transcurrido al menos 6 meses desde la última dosis de la primovacunación. Se puede coadministrar con las demás vacunas recomendadas a esa edad, aunque podria causar más fiebre; por eso, también se podría administrar con una separación de 1 o 2 semanas con las otras vacunas inactivadas inyectables, hasta los 12 meses, para reducir al mínimo la posible reactogenicidad. No se requiere ninguna separación de 1 o 2 semanas con las vacunas MenACWY, SPR, varicela y rotavirus.

Para el resto de las edades la recomendación es de tipo individual con cualquiera de las dos vacunas (4CMenB o MenB-FHbp). También se recomienda a cualquier edad en grupos de riesgo: asplenia anatómica o funcional, déficit de factores de complemento, tratamiento con eculizumab o ravulizumab, receptores de trasplante de progenitores hematopoyéticos, infección por VIH, episodio previo de EMI por cualquier serogrupo y contactos de un caso índice de EMI por MenB en el contexto de un brote epidémico.

Fuente: Asociación Española de Pediatría. Calendario de vacunación de la Asociación Española de Pediatría, recomendaciones para 2021 (15,16).

Este método no sirvió para MenB, el patógeno predominante en cuatro continentes (Europa, Norteamérica y Sudamérica, Norte de África y Australia). El desarrollo de una vacuna frente a MenB continuó planteando retos durante decenios $(20,45,48)$. El polisacárido del patógeno, aparte de poca inmunogenicidad, tras conjugarlo con una proteína transportadora, mostraba una posible reacción cruzada con el tejido humano $(43,49)$. Se temía la inducción de una posible reacción autoinmune por la semejanza del polisacárido MenB con una molécula de adherencia neuronal $(46,48,50,51)$. Por eso, se idearon métodos alternativos para este serogrupo, y la investigación se desvió de la cápsula del patógeno a las proteínas de membrana $(10,46,52)$.

Por esta vía alternativa, a finales de la década de 1980 en Cuba y Noruega y en la de 2000 en Nueva Zelanda se crearon vacunas frente a MenB con la proteína porina $A$
(PorA) de OMV (vesícula de la membrana externa) (53). El problema de estas vacunas era su gran especificidad para ciertas cepas; es decir, no actuaban contra cepas heterólogas del mismo serogrupo $(28,50,53)$. Para solucionar este problema se desarrolló 4CMenB y posteriormente MenBFHbp $(10,54)$.

\section{CMenB}

Los retos para el desarrollo de una vacuna frente a MenB se superaron gracias a la vacunología inversa: $4 C M e n B$ fue la primera vacuna autorizada frente a MenB. Con esta metodología los científicos lograron analizar todo el genoma del patógeno y evaluar así la capacidad de sus proteínas para inducir anticuerpos bactericidas (55). Veintiocho proteínas inducian actividad bactericida del suero frente a un gran número de cepas de MenB. Además de la PorA, las tres más 


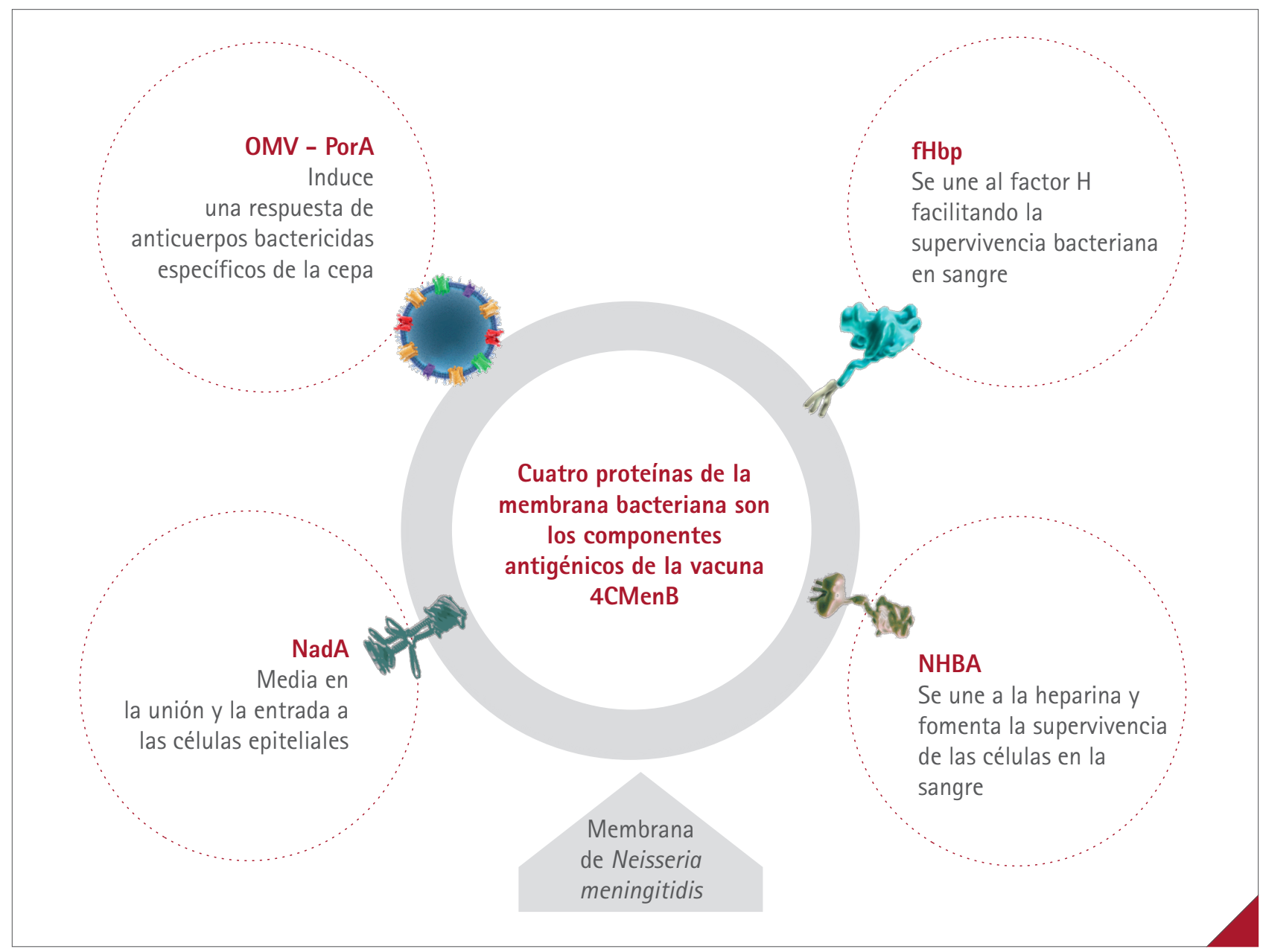

Figura 6 Los cuatro componentes antigénicos de 4CMenB

4CMenB: vacuna de 4 componentes frente al serogrupo meningocócico B; fHbp: proteína de unión al factor H; N. meningitidis: Neisseria meningitidis; NadA: adhesina A de Neisseria; NHBA: antígeno de unión a la heparina de Neisseria; OMV: vesícula de la membrana externa; PorA: proteína porina A

fHbp: esta lipoproteína se localiza en la membrana bacteriana externa de todas las cepas de N. meningitidis (57). Desde esta posición, se une a la proteína del huésped llamada "factor H", cuya misión fundamental es inhibir uno de los mecanismos de defensa naturales del organismo. Asi, la unión del factor H del huésped a la fHbp bacteriana permite la supervivencia del patógeno en el torrente sanguíneo al eludir los mecanismos defensivos del huésped (57). NadA: esta es una proteína expuesta sobre la superficie de N. meningitidis con capacidad para unirse e invadir las células epiteliales respiratorias (95). Está asimismo presente en la mitad de las cepas de la bacteria infecciosa N. meningitidisy en tres de cada cuatro linajes hipervirulentos de los serogrupos B y C (95). NHBA: esta lipoproteína expuesta sobre la superficie se une a la heparina y se ha comprobado que fomenta la supervivencia del patógeno en el torrente sanguíneo (57). Además, se ha propuesto que la NHBA facilita la invasión y colonización del endotelio tras el hallazgo de que cepas de N. meningitidis incapaces de la expresión de NHBA (knock-out) mostraban una adhesión significativamente menor a las células epiteliales (96). El gen codificador de la NHBA está presente en todos los serogrupos de N. meningitidis (96). OMV-PorA: esta es una proteina que induce la reacción inmunitaria del huésped (proteína inmunodominante) y forma parte de la OMV (48). Por eso, PorA tiene una capacidad elevada, pero especifica de cepa, para inducir actividad bactericida (97).

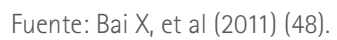

inmunogénicas se seleccionaron como componentes de la vacuna (55). Los cuatro antígenos de $4 \mathrm{CMenB}$ son: proteína de unión al factor $\mathrm{H}$ (fHbp), adhesina A de Neisseria ( $\mathrm{NadA}$ ), antígeno de unión a la heparina de Neisseria (NHBA) y OMV con PorA (48) (figura 6). La inmunización con esta vacuna induce la producción de anticuerpos frente a los cuatro componentes; estos anticuerpos bactericidas se estimulan de nuevo en cuanto entran los patógenos en el torrente sanguíneo (56). Como la expresión de estos cuatro antígenos varía entre las diferentes cepas de MenB, la vacuna protege frente a múltiples cepas de MenB (57). La diana de cada componente es una vía distinta de supervivencia de MenB
$(8,57)$. Casi todas las cepas de MenB contienen genes de más de un componente de $4 \mathrm{CMenB}$. Por eso, los anticuerpos inducidos por la vacuna se dirigen hacia múltiples dianas e inducen una acción bactericida, incluso si la expresión de algún antígeno es más baja (8). La evidencia revela un efecto sinérgico de los anticuerpos inducidos por los cuatro componentes, que refuerza la respuesta bactericida frente a cada antígeno (58). Cuatro antígenos conferirian una amplia cobertura de cepas y 4 CMenB cubriría casi todas las cepas circulantes en Europa, como predijo un gran estudio epidemiológico europeo (59). Además, meningococos diferentes al B podrian expresar estos cuatro antígenos, lo cual 
indicaría una posible protección cruzada frente a otros serogrupos (60-63).

Tras la primera autorización de comercialización en niños $\geq 2$ meses en 2013 en Europa, 4CMenB se ha autorizado para diversos grupos etarios en más de 40 países $(8,10,62,64)$. Las indicaciones actuales de la vacuna incluyen a todos los familiares -comenzando por lactantes de dos meses o más y siguiendo con adolescentes y adultos-, con pautas flexibles de dos o tres dosis, con o sin recuerdo (tabla 2) (56).

En 2015, el Reino Unido fue el primero que incluyó 4CMenB en el PNI sistemática de lactantes con una pauta $2+1$ : las dos primeras dosis a los 2 y 4 meses, respectivamente, y un recuerdo a los 12 (65-68). Esta implementación de la vacuna 4 CMenB en el Reino Unido se acompañó de un impacto vacunal del 75\% (Ratio de tasas de incidencia de 0,25 [intervalo de confianza, IC, del 95\%: 0,19-0,36]) con las tres dosis (68). Varios paises o regiones siguieron después al Reino Unido (9,62,69-74), y añadieron 4CMenB a su programa de inmunización para lactantes de financiación pública (Irlanda, Italia, Andorra, San Marino, Lituania, Australia del Sur [también a los 10 años], República Checa, Portugal, Malta, España [Castilla y León, Islas Canarias]), o recomendaron simplemente la vacunación (Alemania, Austria), o la utilizaron en brotes (Estados Unidos, Canadá).

Disponemos ahora de cantidad de datos sobre el uso de $4 C M e n B$ en una amplia población a nivel mundial que demuestran un excelente rendimiento de la vacuna en la vida real $(8,62,75,76)$. Tras la introducción de 4 CMenB en el PNI para lactantes de Italia, los datos de Toscana y Véneto mostraron un descenso de las tasas brutas de incidencia entre lactantes de 5,54/100.000 a 1,45/100.000 y de 4,65/100.000 a 1,96/100.000, respectivamente (75). En la población general de niños de $\leq 5$ años, la tasa bruta de incidencia se redujo de 1,96/100.000 a 0,94/100.000 en Toscana, y de 1,94/100.000 a 1,79/100.000 en Véneto (75). La efectividad vacunal en esta población ( $\leq 5$ años) fue del 93,6\% (IC del 95\%: 55,4-99,1\%) en Toscana y del 91,0\% (IC del 95\%: 59,9-97,9\%) en Véneto (75). En Portugal se llevó a cabo el primer estudio de casos y controles para evaluar la efectividad de 4 CMenB, así como las consecuencias de la EMI en términos de secuelas y mortalidad, en un amplio grupo de edad (2 meses a 18 años), entre octubre de 2014 hasta marzo de 2019. La efectividad vacunal estimada fue de 79\% (razón de momios: 0.21; IC del 95\%: 0.08-0.55) y no se observaron ni secuelas ni fallecimientos en los casos que habian recibido al menos una dosis de 4CMenB (76). En Canadá, a raíz de un brote de MenB, se inició una campaña de vacunación masiva en 2014 de la población de 2 meses a 20 años de la región de Saguenay-Lac-Saint-Jean (Quebec) $(6,62,77)$. Cuatro años después, el grupo objetivo de la campaña experimentó una llamativa reducción del $96 \%$, de $11,4 / 100.000$ en 2006-2014 a 0,4/100.000 en 2014-2018 ( $p<0,0001$ ), frente al descenso del $59 \%$, de 1,1/100,000 en 2006-2014 a 0,5/100,000 en 2014-2018 ( $p=0,1)$ en los mayores de 20 años (6). El impacto global estimado de la vacunación con 4CMenB fue un descenso del $86 \%$ (IC del 95\%: -2-98\%) en el riesgo de EMI por MenB (6). Además, se registró un perfil tranquilizador de seguridad: $(6,8)$ solo el $0,6 \%$ de los niños de $\leq 2$ años presentaron fiebre (temperatura $\geq 40{ }^{\circ} \mathrm{C}$ ) en los dos primeros días (77). Tranquilizadores son a su vez los datos de seguridad de los $>5$ millones de inyecciones administradas a lactantes británicos desde 2015 (78). Por último, hasta diciembre de 2019 no se registraron nuevos casos de MenB entre casi 34.500 estudiantes (edad media: 15,6 años) de 237 escuelas australianas vacunados con 4CMenB entre 2017 y 2018 mientras participaban en un amplio estudio de portación (79).

Como el intervalo mínimo entre dos dosis a partir de los 2 años es de un mes (56), 4CMenB ofrece una protección temprana frente a $M e n B$, atributo que podria mejorar el cumplimiento. Esta flexibilidad para completar la pauta de vacunación puede ser un factor importante, especialmente de los adolescentes, a menudo reacios a acudir a la cita (80). De hecho, según un análisis reciente de datos de vacunación de más de 78.000 adolescentes y adultos estadounidenses, había más probabilidades de completar la pauta de vacunación frente a MenB cuanto mayor era su flexibilidad (81). En otro estudio se observó que los adolescentes vacunados con 2 dosis de 4CMenB a los 11-17 años mantenían niveles protectores de anticuerpos hasta 7,5 años después de la primovacunación: $44 \%, 84 \%, 29 \%$ y $81 \%$ frente a fHbp, NadA, PorA y NHBA, respectivamente (82). Por tanto, los sujetos vacunados de este grupo etario estarían protegidos durante el período de alto riesgo de padecer EMI (82). Además, el recuerdo administrado a los 4 o 7,5 años desde la primovacunación indujo niveles sustanciales de anticuerpos, por lo que, 4CMenB induce una fuerte respuesta anamnésica. Este hallazgo indica que los sujetos previamente vacunados con 4CMenB tendrian una mejor predisposición inmunológica en caso de brote (82).

Basándose en esta evidencia científica, las guías de la CAV-AEP para 2021 recomiendan incluir la vacunación con 4CMenB en el PNI para todos los lactantes a partir de los 2 meses en España $(15,16)$.

\section{MenB-FHbp}

MenB-FHbp contiene dos variantes inmunológicas de la proteína fHbp (83). En 2014 se autorizó MenB-FHbp en Estados Unidos para personas de 10-25 años (84) y en 2017 en Europa para el grupo etario de $\geq 10$ años (85) con una pauta de dos o tres dosis (tabla 2).

MenB-FHbp se administró a universitarios en Rhode Island, Estados Unidos, tras un brote de MenB $(10,86)$. Los datos clínicos de los estudios de la fase III mostraron una inmunogenicidad superior al umbral en el 86,4-99,5\% de los participantes de 10-18 años después de la tercera dosis, y un perfil de seguridad aceptable (87). No se dispone de datos de la vida real para esta vacuna. 
Tabla 2 Indicaciones, pauta y posología de las vacunas frente al serogrupo meningocócico B en España

\begin{tabular}{|c|c|c|c|c|}
\hline $\begin{array}{l}\text { Vacuna } \\
\text { (nombre comercial) }\end{array}$ & $\begin{array}{l}\text { Edad de la } \\
\text { primera dosis }\end{array}$ & Primovacunación & Intervalo mínimo entre dosis & Dosis de recuerdo \\
\hline \multirow{6}{*}{$\begin{array}{l}\text { 4CMenB } \\
\text { (Bexsero) (56) }\end{array}$} & \multirow[t]{2}{*}{ 2-5 meses } & 3 dosis $\times 0,5 \mathrm{ml}$ i.m. & 1 mes & \multirow{2}{*}{$\begin{array}{l}1 \text { dosis a los } 12-15 \text { meses, } \geq 6 \\
\text { meses después de las dosis } \\
\text { primarias }\end{array}$} \\
\hline & & \multirow[t]{5}{*}{2 dosis $\times 0,5 \mathrm{ml}$ i.m. } & \multirow[t]{3}{*}{2 meses } & \\
\hline & 6-11 meses & & & $\begin{array}{l}1 \text { dosis a los } 12-23 \text { meses, } \geq 2 \\
\text { meses después de las dosis } \\
\text { primarias }\end{array}$ \\
\hline & $12-23$ meses & & & $\begin{array}{l}1 \text { dosis } 12-23 \text { meses después } \\
\text { de las dosis primarias }\end{array}$ \\
\hline & 2-10 años & & \multirow[t]{2}{*}{1 mes } & \multirow[t]{2}{*}{1 dosis para sujetos de riesgo } \\
\hline & $\geq 11$ años & & & \\
\hline \multirow{2}{*}{$\begin{array}{l}\text { MenB-FHbp } \\
\text { (Trumenba) (85) }\end{array}$} & \multirow[t]{2}{*}{$\geq 10$ años } & 2 dosis $\times 0,5 \mathrm{ml}$ i.m. & 6 meses & \multirow[t]{2}{*}{1 dosis para sujetos de riesgo } \\
\hline & & 3 dosis $\times 0,5 \mathrm{ml}$ i.m. & $\begin{array}{l}\text { Segunda dosis } 1 \text { mes después } \\
\text { de la primera y tercera dosis } 4 \\
\text { meses después de la segunda }\end{array}$ & \\
\hline
\end{tabular}

4CMenB: vacuna de 4 componentes frente al serogrupo meningocócico B; i.m.: intramuscular; MenB-FHbp: vacuna de 2 componentes frente a lo serogrupo meningocócico $\mathrm{B}$.

Fuente: resumen de las caracteristicas de los productos Bexsero (56) y Trumenba (85).

\section{ROL DE LOS FARMACÉUTICOS}

La contribución de los farmacéuticos a los servicios de vacunación varía según los países $(88,89)$. En España, la ley asiste a los farmacéuticos para prestar servicios de asesoramiento, dispensación de medicamentos y seguimiento de pacientes (90-92). Además, como los farmacéuticos pueden detectar a las personas de mayor riesgo pueden orientarlas sobre sus necesidades concretas de vacunación, y aconsejarles que acudan a su centro de salud, para que en caso de que fuera adecuado, su médico le prescriba la vacuna indicada a su perfil clínico (86).

Informar al público de las vacunas forma parte del quehacer diario del farmacéutico (93): las encuestas en farmacias comunitarias revelan que más del $90 \%$ de los pacientes preguntan sobre vacunas (94). En efecto, los farmacéuticos son canales esenciales de información válida y cuentan con la confianza mayoritaria del público $(88,93)$. Estos profesionales sanitarios, al ser más accesibles al público (91), a menudo se convierten en educadores de la población sobre los beneficios de las vacunas y ayudan a reforzar la concienciación sobre la importancia de completar las pautas vacunales $(88,89)$. El rol educativo de los farmacéuticos está respaldado con programas formativos, que no solo incluyen información básica sobre manipulación y conservación de vacunas, sino también conocimientos técnicos de vacunas como indicaciones, contraindicaciones, datos de seguridad o detección de posibles efectos secundarios (91).

En el caso de la vacunación meningocócica, esperamos que la información ofrecida en esta revisión sirva de referencia a los farmacéuticos en sus respuestas a padres y pacientes sobre las ventajas, el calendario o las dosis de recuerdo de las vacunas. Estas medidas ayudarán además a los farmacéuticos a cumplir su misión, especialmente en épocas complicadas de pandemia (17).

\section{CONCLUSIONES}

La EMI es una infección bacteriana poco frecuente pero devastadora que puede cursar con meningitis y sepsis. Puede ocasionar la muerte o amputación de miembros, convulsiones, ictus, problemas de audición u otras secuelas graves. Sin embargo, es una enfermedad prevenible mediante vacunación. La OMS se ha fijado como objetivo derrotar a la meningitis para 2030.

Si bien hace años que se dispone de vacunas frente a cuatro serogrupos responsables de la EMI ( $, C, W$ e $Y$ ), no se había desarrollado ninguna frente a $M e n B$, el serogrupo causante de la mayoría de las infecciones en Europa, América y Australia. La investigación en vacunas frente a este serogrupo supuso un desafío para los investigadores. El desarrollo de 4CMenB y MenB-FHbp se logró hace bien poco. Ambas se han utilizado en brotes. EI CAV-AEP recomienda la administración sistemática de 4CMenB a lactantes. Los datos favorables de efectividad, impacto y seguridad obtenidos tras administrar millones de dosis de 4CMenB demuestran que la vacuna es efectiva y bien tolerada y previene frente al serogrupo que más EMI produce en España. 
Así pues, al margen de que la vacunación frente a la EMI se incluya en el PNI sistemático, la actuación de los farmacéuticos comunitarios es clave para asesorar debidamente a los padres para que estos puedan tomar una decisión informada y respaldando así las recomendaciones de los pediatras.

\section{AGRADECIMIENTOS}

Los autores expresan su agradecimiento a Amir Diab Cáceres y Natalia González Quero (GSK, España) por el apoyo científico durante el desarrollo de este manuscrito. Los autores también desean agradecer la asistencia editorial y la coordinación del manuscrito por parte de la plataforma Business \&t Decision Life Sciences, en nombre de GSK. Grégory Leroux coordinó el desarrollo del manuscrito y la asistencia editorial y Athanasia Benekou proporcionó ayuda para la redacción.

\section{REFERENCIAS BIBLIOGRÁFICAS}

1. Caugant DA, Brynildsrud OB. Neisseria meningitidis: using genomics to understand diversity, evolution and pathogenesis. Nat Rev Microbiol. 2020;18(2):84-96. doi:10.1038/s41579-019-0282-6

2. Pace $D$, Pollard AJ. Meningococcal disease: clinical presentation and sequelae. Vaccine. 2012;30 Suppl 2:B3-9. doi:10.1016/j.vaccine.2011.12.062

3. World Health Organization. Meningitis. Overview. 2020. Disponible en: https://www.who.int/emergencies/diseases/meningitis/en/. Meningococcal meningitis. Key facts. 2018. Disponible en: https://www.who. int/en/news-room/fact-sheets/detail/meningococcal-meningitis. Defeating bacterial meningitis by 2030. 2018. Disponible en: https:// www.who.int/emergencies/diseases/meningitis/meningitis-2030. pdf?ua=1\&ua=1. Baseline situation analysis. 2019. Disponible en: https://www.who.int/immunization/research/BSA_20feb2019.pd$f$ ?ua $=1$. A roadmap. Draft goals and milestones. 2019. Disponible en: https://www.who.int/immunization/sage/meetings/2019/april/1_DEFEATING_MENINGITIS_BY_2030_A_ROADMAP_Draft_goals_and_ milestones.pdf?ua=1. Wilton Park. Meningitis Research Foundation. A global vision for meningitis by 2030 and an action plan to get there. 2017. Disponible en: https://www.wiltonpark.org.uk/wp-content/uploads/WP1521-Report.pdf. [Consultado 3/9/2020].

4. Cabellos C, Pelegrín I, Benavent E, Gudiol F, Tubau F, Garcia-Somoza $D$, et al. Invasive Meningococcal Disease: What We Should Know, Before It Comes Back. Open Forum Infect Dis. 2019;6(3):ofz059. doi:10.1093/ofid/ofz059

5. Dwilow R, Fanella S. Invasive meningococcal disease in the 21st century-an update for the clinician. Curr Neurol Neurosci Rep. 2015;15(3):2. doi:10.1007/s11910-015-0524-6

6. Deceuninck G, Lefebvre B, Tsang R, Betala-Belinga JF, De Serres G, De Wals P. Impact of a mass vaccination campaign against Serogroup $B$ meningococcal disease in the Saguenay-Lac-Saint-Jean region of Quebec four years after its launch. Vaccine. 2019;37(31):4243-4245. doi:10.1016/j.vaccine.2019.06.021

7. Soeters HM, McNamara LA, Whaley M, Wang X, Alexander-Scott $N$, Kanadanian KV, et al. Serogroup B Meningococcal Disease Outbreak and Carriage Evaluation at a College - Rhode Island, 2015. MMWR Morb Mortal Wkly Rep. 2015;64(22):606-7.

8. Abad R, Martinón-Torres F, Santolaya ME, Banzhoff A, González-Inchausti C, Graña MG, et al. [From a pathogen's genome to an ef- fective vaccine: the four-component meningococcal serogroup $B$ vaccine]. Rev Esp Quimioter. 2019;32(3):208-16.

9. European Centre for Disease Prevention and Control. Expert opinion on the introduction of the meningococcal B (4CMenB) vaccine in the EU/EEA. 2017. Disponible en: https://www.ecdc.europa.eu/ sites/default/files/documents/Introduction-of-4CMenB-vaccine.pdf [Consultado 3/9/2020].

10. Wilkins $A L$, Snape MD. Emerging clinical experience with vaccines against group B meningococcal disease. Vaccine. 2018;36(36):54705476. doi:10.1016/j.vaccine.2017.07.056

11. Boletín Oficial de Castilla y León. Consejería de Sanidad. Núm. 78 Jueves, 25 de abril de 2019 Pág. 20762. Disponible en: http://bocyl. jcyl.es/boletines/2019/04/25/pdf/BOCYL-D-25042019-41.pdf. [Consultado 3/9/2020].

12. Boletín Oficial de Canarias. Consejería de Sanidad. 3325 ORDEN de 28 de junio de 2019, por la que se aprueba el Calendario Vacunal para todas las edades de la vida en la Comunidad Autónoma de Canarias. BOC No 126. Miércoles 3 de julio de 2019 - 3325. Disponible en: http://www.gobiernodecanarias.org/boc/2019/126/001.html [Consultado 3/9/2020].

13. Grupo de trabajo vacunación frente a EMI de la Ponencia de Programa y Registro de Vacunaciones. Recomendaciones de vacunación frente a enfermedad meningocócica invasiva. Comisión de Salud Pública del Consejo Interterritorial del Sistema Nacional de Salud. Ministerio de Sanidad, Consumo y Bienestar Social, Marzo 2019. Disponible en: https://www.mscbs.gob.es/profesionales/saludPublica/prevPromocion/vacunaciones/docs/Recomendaciones_Vacunacion_Meningococo.pdf. [Consultado 3/9/2020].

14. Junta de Andalucia Consejería de Salud y Familias. Calendario de vacunaciones recomendado para todas las edades - infancia, adolescencia, y edad adulta - Andalucia 2020. Instrucción DGSPyOF-8/2019. Disponible en: https://www.juntadeandalucia.es/export/drupaljda/ csafaCalendarioVacunacion2020.pdf. [Consultado 13/10/2020].

15. Asociación Española de Pediatría. Comité Asesor de Vacunas. Calendario de Vacunaciones de la Asociación Española de Pediatría. Razones y bases de las recomendaciones 2021. 1 de enero de 2021. Disponible en: https://vacunasaep.org/profesionales/calendario-de-vacunaciones-de-la-aep-2021. [Consultado 15/1/2021].

16. Álvarez Garcia FJ, Cilleruelo Ortega MJ, Álvarez Aldeán J, Garcés-Sánchez M, Garcia Sánchez N, Garrote Llanos E, et al. [Immunisation schedule of the Pediatric Spanish Association: 2021 recommendations]. An Pediatr (Barc). 2021;94(1):53.e1-53.e10. doi:10.1016/j. anpedi.2020.10.002

17. World Health Organization. Maintaining essential health services: operational guidance for the COVID-19 context interim guidance. 2020. Disponible en: https://www.who.int/publications/i/item/ WHO-2019-nCoV-essential-health-services-2020.1. [Consultado 3/ 9/2020].

18. GAVI. At least 80 million children at risk of disease as COVID-19 disrupts vaccination efforts, warn Gavi, WHO and UNICEF. 22 May 2020. Disponible en: https://www.gavi.org/news/media-room/least80-million-children-risk-disease-covid-19-disrupts-vaccinationefforts. [Consultado 3/9/2020].

19. European Centre for Disease Prevention and Control. Surveillance Atlas of Infectious Diseases. 2018. Disponible en: https://atlas.ecdc.europa. eu/public/index.aspx?Dataset=27\&tHealthTopic $=36$. Factsheet about meningococcal disease. 2019. Disponible en: https://www.ecdc.europa. eu/en/meningococcal-disease/factsheet. [Consultado 3/9/2020].

20. Acevedo R, Bai X, Borrow R, Caugant DA, Carlos J, Ceyhan M, et al. The Global Meningococcal Initiative meeting on prevention of meningococcal disease worldwide: Epidemiology, surveillance, hypervirulent strains, antibiotic resistance and high-risk populations. Expert Rev Vaccines. 2019;18(1):15-30. doi:10.1080/14760584.2019.15575 20 
21. Read RC. Neisseria meningitidis; clones, carriage, and disease. Clin Microbiol Infect. 2014;20(5):391-395. doi:10.1111/1469-0691.12647

22. Ministerio de Ciencia, Innovación y Universidades. Enfermedad meningocócica, Vigilancia de la temporada 2017-2018. Resultados de la Red Nacional de Vigilancia Epidemiológica. 2019. Disponible en: https://www.isciii.es/QueHacemos/Servicios/VigilanciaSaludPublicaRENAVE/EnfermedadesTransmisibles/Documents/archivos\%20A-Z/ Enfer_Meningoc\%C3\%B3cica/RENAVE_EMI-2017-18.pdf. [Consultado 3/9/2020].

23. Wang B, Santoreneos R, Giles L, Haji Ali Afzali H, Marshall H. Case fatality rates of invasive meningococcal disease by serogroup and age: A systematic review and meta-analysis. Vaccine. 2019;37(21):27682782. doi:10.1016/j.vaccine.2019.04.020

24. Peterson ME, Li Y, Bita A, Moureau A, Nair H, Kyaw MH, et al. Meningococcal serogroups and surveillance: a systematic review and survey. J Glob Health. 2019;9(1):010409. doi:10.7189/jogh.09.010409

25. Whittaker R, Dias JG, Ramliden $M$, Ködmon C, Economopoulou A, Beer $N$, et al. The epidemiology of invasive meningococcal disease in EU/EEA countries, 2004-2014. Vaccine. 2017;35(16):2034-2041. doi:10.1016/j.vaccine.2017.03.007

26. Christensen $H$, May M, Bowen L, Hickman M, Trotter CL. Meningococcal carriage by age: a systematic review and meta-analysis. Lancet Infect Dis. 2010;10(12):853-861. doi:10.1016/S14733099(10)70251-6

27. Pelton SI. The Global Evolution of Meningococcal Epidemiology Following the Introduction of Meningococcal Vaccines. J Adolesc Health. 2016;59(2):S3-S11. doi:10.1016/j.jadohealth.2016.04.012

28. Balmer $P$, Burman $C$, Serra L, York $\sqcup$. Impact of meningococcal vaccination on carriage and disease transmission: A review of the literature. Hum Vaccin Immunother. 2018;14(5):1118-1130. doi:10.1080 /21645515.2018.1454570

29. Stephens DS. Biology and pathogenesis of the evolutionarily successful, obligate human bacterium Neisseria meningitidis. Vaccine. 2009;27(Suppl 2):B71-B77. doi:10.1016/j.vaccine.2009.04.070

30. Coureuil $M$, Lécuyer $H$, Bourdoulous $S$, Nassif X. A journey into the brain: insight into how bacterial pathogens cross blood-brain barriers. Nat Rev Microbiol. 2017;15(3)149-159. doi:10.1038/nrmicro.2016.178

31. Pathan N, Faust SN, Levin M. Pathophysiology of meningococcal meningitis and septicaemia. Arch Dis Child. 2003;88(7):601-607. doi:10.1136/adc.88.7.601

32. van de Beek D, de Gans J, Spanjaard L, Weisfelt M, Reitsma JB, Vermeulen M. Clinical features and prognostic factors in adults with bacterial meningitis. N Engl J Med. 2004;351(18):1849-1859. doi:10.1056/NEJMoa040845

33. Moore JE. Meningococcal Disease Section 3: Diagnosis and Management: MeningoNI Forum (see page 87(2) 83 for full list of authors). Ulster Med J. 2018;87(2):94-98.

34. Campbell H, Parikh SR, Borrow R, Kaczmarski E, Ramsay ME, Ladhani SN. Presentation with gastrointestinal symptoms and high case fatality associated with group W meningococcal disease (MenW) in teenagers, England, July 2015 to January 2016. Euro Surveill. 2016;21(12). doi:10.2807/1560-7917.ES.2016.21.12.30175

35. Chaudhuri A, Martinez-Martin P, Kennedy PG, Andrew Seaton $R$, Portegies $\mathrm{P}$, Bojar $\mathrm{M}$, et al. EFNS guideline on the management of community-acquired bacterial meningitis: report of an EFNS Task Force on acute bacterial meningitis in older children and adults. Eur J Neurol. 2008;15(7):649-659. doi:10.1111/j.14681331.2008.02193.x

36. Køster-Rasmussen R, Korshin A, Meyer CN. Antibiotic treatment delay and outcome in acute bacterial meningitis. J Infect. 2008;57(6):449-454. doi:10.1016/j.jinf.2008.09.033

37. Proulx N, Fréchette $D$, Toye $B$, Chan J, Kravcik S. Delays in the administration of antibiotics are associated with mortality from adult acute bacterial meningitis. OJM. 2005;98(4):291-298. doi:10.1093/ qjmed/hci047

38. Thompson MJ, Ninis N, Perera R, Mayon-White R, Phillips C, Bailey L, et al. Clinical recognition of meningococcal disease in children and adolescents. Lancet. 2006;367(9508):397-403. doi:10.1016/S01406736(06)67932-4

39. van de Beek D, Cabellos C, Dzupova O, Esposito S, Klein M, Kloek AT, et al. ESCMID guideline: diagnosis and treatment of acute bacterial meningitis. Clin Microbiol Infect. 2016;22 Suppl 3:S37-62. doi:10.1016/j.cmi.2016.01.007

40. McGill F, Heyderman RS, Michael BD, Defres $S$, Beeching NJ, Borrow $R$, et al. The UK joint specialist societies guideline on the diagnosis and management of acute meningitis and meningococcal sepsis in immunocompetent adults. J Infect. 2016;72(4):405-438. doi:10.1016/j.jinf.2016.01.007

41. Cohn AC, MacNeil JR, Clark TA, Ortega-Sanchez IR, Briere EZ, Meissner $\mathrm{HC}$, et al. Prevention and control of meningococcal disease: recommendations of the Advisory Committee on Immunization Practices (ACIP). MMWR Recomm Rep. 2013;62(RR-2):1-28.

42. McNamara LA, MacNeil JR, Cohn AC, Stephens DS. Mass chemoprophylaxis for control of outbreaks of meningococcal disease. Lancet Infect Dis. 2018;18(9):e272-e81. doi:10.1016/S1473-3099(18)30124-5

43. Artenstein AW. Vaccines: A Biography: Springer New York: Springer-Verlag; 2010. 402 p.

44. Goldschneider I, Gotschlich EC, Artenstein MS. Human immunity to the meningococcus. II. Development of natural immunity. J Exp Med. 1969;129(6):1327-1348. doi:10.1084/jem.129.6.1327

45. Vipond $C_{1}$ Care $R$, Feavers IM. History of meningococcal vaccines and their serological correlates of protection. Vaccine. 2012;30 Suppl 2:B10-B17. doi:10.1016/j.vaccine.2011.12.060

46. Dretler AW, Rouphael NG, Stephens DS. Progress toward the global control of Neisseria meningitidis: 21st century vaccines, current guidelines, and challenges for future vaccine development. Hum Vaccin Immunother. 2018;14(5):1146-1160. doi:10.1080/21645515.2018.1451810

47. Maiden MC, Ibarz-Pavón $A B$, Urwin R, Gray SJ, Andrews NJ, Clarke $\mathrm{SC}$, et al. Impact of meningococcal serogroup $C$ conjugate vaccines on carriage and herd immunity. J Infect Dis. 2008;197(5):737-743. doi:10.1086/527401

48. Bai $X$, Findlow J, Borrow R. Recombinant protein meningococcal serogroup B vaccine combined with outer membrane vesicles. Expert Opin Biol Ther. 2011;11(7):969-985. doi:10.1517/14712598.2011.585965

49. Finne J, Leinonen M, Mäkelä PH. Antigenic similarities between brain components and bacteria causing meningitis. Implications for vaccine development and pathogenesis. Lancet. 1983;2(8346):355-357. doi:10.1016/s0140-6736(83)90340-9

50. Crum-Cianflone N, Sullivan E. Meningococcal Vaccinations. Infect Dis Ther. 2016;5(2):89-112. doi:10.1007/s40121-016-0107-0

51. Beninati C, Arseni S, Mancuso G, Magliani W, Conti S, Midiri A, et al. Protective immunization against group $B$ meningococci using anti-idiotypic mimics of the capsular polysaccharide. J Immunol. 2004;172(4):2461-2468. doi:10.4049/jimmunol.172.4.2461

52. Feavers IM, Maiden MCJ. Recent Progress in the Prevention of Serogroup B Meningococcal Disease. Clin Vaccine Immunol. 2017;24(5):e00566-16. doi:10.1128/CVI.00566-16

53. Holst J, Oster P, Arnold R, Tatley MV, Naess LM, Aaberge IS, et al. Vaccines against meningococcal serogroup $B$ disease containing outer membrane vesicles (OMV): lessons from past programs and implications for the future. Hum Vaccin Immunother. 2013;9(6):1241-1253. doi:10.4161/hv.24129

54. Rivero-Calle I, Raguindin PF, Gómez-Rial J, Rodriguez-Tenreiro C, Martinón-Torres F. Meningococcal Group B Vaccine For The Prevention Of Invasive Meningococcal Disease Caused By Neisseria meningitidis Serogroup B. Infect Drug Resist. 2019;12:3169-3188. doi:10.2147/IDR.S159952 
55. Del Tordello E, Serruto D. Functional genomics studies of the human pathogen Neisseria meningitidis. Brief Funct Genomics. 2013;12(4):328-340. doi:10.1093/bfgp/elt018

56. European Medicines Agency. Bexsero - Meningococcal group B Vaccine. EPAR - Product Information. 2012. Disponible en: https:// www.ema.europa.eu/en/documents/product-information/bexsero-epar-product-information_en.pdf. [Consultado 3/9/2020].

57. Watson PS, Novy PL, Friedland LR. Potential benefits of using a multicomponent vaccine for prevention of serogroup B meningococcal disease. Int J Infect Dis. 2019;85:22-27. doi:10.1016/j. ijid.2019.05.019

58. Rappuoli R, Pizza M, Masignani V, Vadivelu K. Meningococcal B vaccine (4CMenB): the journey from research to real world experience. Expert Rev Vaccines. 2018;17(12):1111-1121. doi:10.1080/14760584 .2018.1547637

59. Vogel U, Taha MK, Vazquez JA, Findlow J, Claus $H_{1}$ Stefanelli $P$, et al. Predicted strain coverage of a meningococcal multicomponent vaccine (4CMenB) in Europe: a qualitative and quantitative assessment. Lancet Infect Dis. 2013;13(5):416-425. doi:10.11016/\$14733099(13)70006-9

60. Ladhani SN, Giuliani MM, Biolchi A, Pizza M, Beebeejaun K, Lucidarme J, et al. Effectiveness of Meningococcal B Vaccine against Endemic Hypervirulent Neisseria meningitidis W Strain, England. Emerg Infect Dis. 2016;22(2):309-311. doi:10.3201/eid2202.150369

61. Hong $E_{\text {, Giuliani } M M}$, Deghmane $A E_{1}$ Comanducci $M$, Brunelli $B$, Dull $P$, et al. Could the multicomponent meningococcal serogroup $B$ vaccine $(4 \mathrm{CMen} B)$ control Neisseria meningitidis capsular group X outbreaks in Africa? Vaccine. 2013;31(7):1113-1116. doi:10.1016/j. vaccine.2012.12.022

62. Isitt $C$, Cosgrove $C A$, Ramsay ME, Ladhani SN. Success of $4 C M e n B$ in preventing meningococcal disease: evidence from real-world experience. Arch Dis Child. 2020;105(8):784-790. doi:10.1136/archdischild-2019-318047

63. Ladhani SN, Campbell H, Andrews N, Parikh SR, White J, Edelstein $M_{1}$ et al. First real world evidence of meningococcal group $B$ vaccine, $4 C M e n B$, protection against meningococcal group $W$ disease; prospective enhanced national surveillance, England. Clin Infect Dis. 2020. [Epub antes de imprimir]. doi:10.1093/cid/ciaa1244

64. Watson PS, Turner DP. Clinical experience with the meningococcal $B$ vaccine, Bexsero( $\left({ }^{\circledR}\right)$ : Prospects for reducing the burden of meningococcal serogroup B disease. Vaccine. 2016;34(5):875-880. doi:10.1016/j.vaccine.2015.11.057

65. Public Health England. MenB vaccination: introduction from September 2015. 2015. Disponible en: https://www.gov.uk/government/ publications/menb-vaccination-introduction-from-1-september-2015. [Consultado 3/9/2020].

66. Parikh SR, Andrews NJ, Beebeejaun K, Campbell H, Ribeiro S,

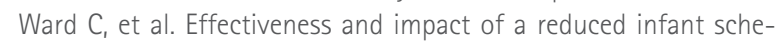
dule of $4 C M e n B$ vaccine against group $B$ meningococcal disease in England: a national observational cohort study. Lancet. 2016;388(10061):2775-2782. doi:10.1016/S0140-6736(16)31921-3

67. Ladhani SN, Ramsay M, Borrow R, Riordan A, Watson JM, Pollard AJ. Enter $B$ and $W$ : two new meningococcal vaccine programmes launched. Arch Dis Child. 2016;101(1):91-95. doi:10.1136/archdischild-2015-308928

68. Ladhani SN, Andrews N, Parikh SR, Campbell H, White J, Edelstein M, et al. Vaccination of Infants with Meningococcal Group B Vaccine (4CMenB) in England. N Engl J Med. 2020;382:309-317. doi:10.1056/ NEJMoa1901229

69. Zákon č. 48/1997 Sb. Zákon o veřejném zdravotním pojištění a o změněa dopIněni některých souvisejícich zákonů [Act on Public Health Insurance and on Amendments to Certain Related Acts]. 1997. Disponible en: https://www.zakonyprolidi.cz/cs/1997-48. [Consultado $3 / 9 / 2020]$.
70. SAÚDE. Gabinete do Secretário de Estado da Saúde. Despacho n. ${ }^{\circ}$ 12434/2019. Diário da República, 2. ${ }^{a}$ série. N. ${ }^{\circ} 250.30$ de dezembro de 2019. Pág. 30. 2019. Disponible en: https://dre.pt/application/ conteudo/127608823. [Consultado 8/10/2020].

71. Government of Malta. Primary Child \& Youth Health \& Immunisation. Vaccines. 2020. Disponible en: https://deputyprimeminister.gov. mt/en/phc/pchyhi/Pages/Vaccines.aspx. [Consultado 8/10/2020].

72. Government of South Australia. Meningococcal B Immunisation Program. 2020. Disponible en: https://www.sahealth.sa.gov.au/wps/ $w \mathrm{~cm} /$ connect/public+content/sa+health+internet/conditions/immunisation/immunisation+programs/meningococcal+b+immunisation+program. [Consultado 8/10/2020].

73. Parikh SR, Campbell H, Bettinger JA, Harrison LH, Marshall HS, Martinon-Torres $F$, et al. The everchanging epidemiology of meningococcal disease worldwide and the potential for prevention through vaccination. J Infect. 2020;81(4):483-498. doi:10.1016/j. jinf.2020.05.079

74. Pizza M, Bekkat-Berkani R, Rappuoli R. Vaccines against Meningococcal Diseases. Microorganisms. 2020;8(10):1521. doi:10.3390/microorganisms 8101521

75. Azzari C, Moriondo M, Nieddu F, Guarnieri V, Lodi L, Canessa C, et al. Effectiveness and Impact of the 4 CMenB Vaccine against Group B Meningococcal Disease in Two Italian Regions Using Different Vaccination Schedules: A Five-Year Retrospective Observational Study (2014-2018). Vaccines (Basel). 2020;8(3):E469. doi:10.3390/vaccines 8030469

76. Rodrigues FMP, Marlow R, Simões MJ, Danon L, Ladhani S, Finn A. Association of Use of a Meningococcus Group B Vaccine With Group B Invasive Meningococcal Disease Among Children in Portugal. JAMA. 2020;324(21):2187-2194. doi:10.1001/jama.2020.20449

77. De Serres G, Billard MN, Gariépy MC, Rouleau I, Toth E, Landry M, et al. Short-term safety of $4 C M e n B$ vaccine during a mass meningococcal B vaccination campaign in Quebec, Canada. Vaccine. 2018;36(52):8039-8046. doi:10.1016/j.vaccine.2018.10.095

78. Public Health England. The impact of the MenB vaccine. 2020. Disponible en: https://publichealthengland.exposure.co/the-impact-ofthe-menb-vaccine. [Consultado 3/9/2020].

79. Marshall HS, McMillan M, Koehler AP, Lawrence A, Sullivan TR, MacLennan JM, et al. Meningococcal B Vaccine and Meningococcal Carriage in Adolescents in Australia. N Engl J Med. 2020;382:318-327. doi:10.1056/NEJMoa1900236

80. Niccolai LM, Hansen CE. Suboptimal uptake of meningococcal vaccines among older adolescents: Barriers, solutions, and future research directions. Hum Vaccin Immunother. 2020;16(12):32083212. doi:10.1080/21645515.2020.1754052

81. Packnett E, Irwin DE, Novy P, Watson PS, Whelan J, Moore-Schiltz L, et al. Meningococcal-group $B$ (MenB) vaccine series completion and adherence to dosing schedule in the United States: A retrospective analysis by vaccine and payer type. Vaccine. 2019;37(39):58995908. doi:10.1016/j.vaccine.2019.06.065

82. Watson PS, Novy P, Bekkat-Berkani R, Strubbe F, Banzhoff A. Optimizing the timing of $4 \mathrm{CMen} B$ vaccination in adolescents and young adults based on immune persistence and booster response data. Expert Rev Vaccines. 2019;18(4):343-352. doi:10.1080/14760584.2 019.1580579

83. Gandhi A, Balmer $P$, York $\sqcup$. Characteristics of a new meningococcal serogroup B vaccine, bivalent rLP2086 (MenB-FHbp; Trumenba ${ }^{\circledR}$ ). Postgrad Med. 2016;128(6):548-556. doi:10.1080/00325481.2016.1 203238

84. U.S. Food and Drug Administration. Trumenba (Meningococcal Group B Vaccine). Suspension for intramuscular injection. Highlights of prescribing information. 2018. Disponible en: https://www. fda.gov/files/vaccines,\%20blood\%20\&\%20biologics/published/Package-Insert---TRUMENBA.pdf. [Consultado 3/9/2020]. 
85. European Medicines Agency. Trumemba - Meningococcal group B Vaccine. EPAR - Product Information. 2017. Disponible en: https:// www.ema.europa.eu/en/documents/product-information/trumenba-epar-product-information_en.pdf. [Consultado 3/9/2020].

86. Soeters HM, Whaley M, Alexander-Scott N, Kanadanian KV, MacNeil $J R_{1}$ Martin SW, et al. Meningococcal Carriage Evaluation in Response to a Serogroup B Meningococcal Disease Outbreak and Mass Vaccination Campaign at a College-Rhode Island, 2015-2016. Clin Infect Dis. 2017;64(8):1115-1122. doi:10.1093/cid/cix091

87. Burman C, Alderfer J, Snow VT. A review of the immunogenicity, safety and current recommendations for the meningococcal serogroup B vaccine, MenB-FHbp. J Clin Pharm Ther. 2020;45(2):270281. doi:10.1111/jcpt.13083

88. International Pharmaceutical Federation. An overview of current pharmacy impact on immunisation. A global report. 2016. Disponible en: https://www.fip.org/www/streamfile.php?filename=fip/publications/FIP_report_on_Immunisation.pdf. [Consultado 21/10/2020].

89. Poudel A, Lau ETL, Deldot M, Campbell C, Waite NM, Nissen LM. Pharmacist role in vaccination: Evidence and challenges. Vaccine. 2019;37(40):5939-5945. doi:10.1016/j.vaccine.2019.08.060

90. Gastelurrutia MA, Faus MJ, Martinez-Martínez F. Primary health care policy and vision for community pharmacy and pharmacists in Spain. Pharm Pract (Granada). 2020;18(2):1999. doi:10.18549/ PharmPract.2020.2.1999

91. General Pharmaceutical Council of Spain. Good Pharmacy Practice in Spanish Community Pharmacy. Madrid, July 2013. Disponible en: https:// www.portalfarma.com/Profesionales/Buenas-practicas-profesionales/ Documents/Buenas-Practicas-Ingles.pdf. [Consultado 21/10/2020].
92. Foro de Atención Farmacéutica-Farmacia Comunitaria (Foro AF-FC). Guía práctica para los Servicios Profesionales Farmacéuticos Asistenciales en la Farmacia Comunitaria. Madrid: Consejo General de Colegios Oficiales de Farmacéuticos; 2019. Disponible en: https:// www.portalfarma.com/inicio/serviciosprofesionales/forofarmaciacomunitaria/Documents/2021-guia-practica-spfa.pdf. [Consultado 6/4/2021].

93. Isenor JE, Bowles SK. Opportunities for pharmacists to recommend and administer routine vaccines. Can Pharm J (0tt). 2019;152(6):401405. doi:10.1177/1715163519878473

94. Scarpitta F, Restivo V, Bono CM, Sannasardo CE, Vella C, Ventura G, et al. The role of the Community Pharmacist in promoting vaccinations among general population according to the National Vaccination Plan 2017-2019: results from a survey in Sicily, Italy. Ann Ig. 2019;31(2 Suppl 1):25-35. http://dx.doi.org/10.7416/ ai.2019.2274

95. Comanducci M, Bambini S, Brunelli B, Adu-Bobie J, Aricò B, Capecchi $B$, et al. NadA, a novel vaccine candidate of Neisseria meningitidis. J Exp Med. 2002;195(11):1445-1454. doi:10.1084/jem.20020407

96. Vacca I, Del Tordello E, Gasperini G, Pezzicoli A, Di Fede M, Rossi

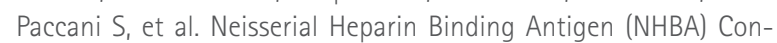
tributes to the Adhesion of Neisseria meningitidis to Human Epithelial Cells. PLoS One. 2016;11(10):e0162878. doi:10.1371/journal. pone. 0162878

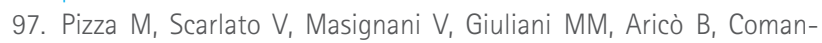
ducci $M$, et al. Identification of vaccine candidates against serogroup $\mathrm{B}$ meningococcus by whole-genome sequencing. Science. 2000;287(5459):1816-1820. doi:10.1126/science.287.5459.1816 